\title{
Additively manufactured mirrors for CubeSats
}

\author{
Carolyn Atkins, William Brzozowski, Naomi Dobson, \\ Maria Milanova, Stephen Todd, David Pearson, \\ Cyril Bourgenot, David Brooks, Robert Snell, \\ Wenjuan Sun, Peter Cooper, Simon G Alcock, \\ loana-Theodora Nistea
}

\section{Published version information:}

Citation: C Atkins et al. "Additively manufactured mirrors for CubeSats." Proceedings of SPIE, vol. 11116 (2019): 1111616. Is in: Astronomical Optics: Design, Manufacture, and Test of Space and Ground Systems II, proceedings of SPIE Optical Engineering + Applications, San Diego, California, USA, 11-15 Aug 2019.

DOI: $\underline{10.1117 / 12.2528119}$

(C) 2019 Society of Photo Optical Instrumentation Engineers (SPIE). One print or electronic copy may be made for personal use only. Systematic reproduction and distribution, duplication of any material in this publication for a fee or for commercial purposes, or modification of the contents of the publication are prohibited.

This version is made available in accordance with publisher policies. Please cite only the published version using the reference above. This is the citation assigned by the publisher at the time of issuing the APV. Please check the publisher's website for any updates. 


\section{Additively manufactured mirrors for CubeSats}

Carolyn Atkins, William Brzozowski, Naomi Dobson, Maria Milanova, Stephen Todd, et al.

Carolyn Atkins, William Brzozowski, Naomi Dobson, Maria Milanova, Stephen Todd, David Pearson, Cyril Bourgenot, David Brooks, Robert Snell, Wenjuan Sun, Peter Cooper, Simon G Alcock, loana-Theodora Nistea, "Additively manufactured mirrors for CubeSats," Proc. SPIE 11116, Astronomical Optics: Design, Manufacture, and Test of Space and Ground Systems II, 1111616 (16 September 2019); doi: 10.1117/12.2528119

Event: SPIE Optical Engineering + Applications, 2019, San Diego, California, United States 


\title{
Additively manufactured mirrors for CubeSats
}

\author{
Carolyn Atkins*a, William Brzozowski ${ }^{\mathrm{a}}$, Naomi Dobson ${ }^{\mathrm{a}}$, Maria Milanova ${ }^{\mathrm{a}}$, Stephen Todd $^{\mathrm{a}}$, \\ David Pearson ${ }^{\mathrm{b}}$, Cyril Bourgenot ${ }^{\mathrm{c}}$, David Brooks ${ }^{\mathrm{d}}$, Robert Snelle, Wenjuan Sun ${ }^{\mathrm{f}}$, Peter \\ Cooper $^{\mathrm{f}}$, Simon G. Alcock ${ }^{\mathrm{g}}$, and Ioana-Theodora Nistea ${ }^{\mathrm{g}}$ \\ ${ }^{a}$ UK Astronomy Technology Centre, Royal Observatory, Edinburgh, EH9 3HJ, UK \\ ${ }^{\mathrm{b}} \mathrm{RAL}$ Space, Harwell Science \& Innovation Campus, OX11 0QX, UK \\ ${ }^{c}$ Durham University, NETPark Research Institute, Sedgefield, TS21 3FB, UK \\ ${ }^{\mathrm{d}}$ University College London, Department of Physics and Astronomy, London, WC1E 6BT, UK \\ eDept of Materials Science and Engineering, University of Sheffield, Sheffield, S1 3JD, UK \\ ${ }^{\mathrm{f}}$ National Physical Laboratory, Teddington, Middlesex, TW11 0LW, UK \\ ${ }^{g}$ Diamond Light Source, Harwell Science \& Innovation Campus, OX11 0QX, UK
}

\begin{abstract}
Additive manufacturing (AM; 3D printing) is a fabrication process that builds an object layer-upon-layer and promotes the use of structures that would not be possible via subtractive machining. Prototype AM metal mirrors are increasingly being studied in order to exploit the advantage of the broad AM design-space to develop intricate lightweight structures that are more optimised for function than traditional open-back mirror lightweighting.

This paper describes a UK Space Agency funded project to design and manufacture a series of lightweighted AM mirrors to fit within a 3 U CubeSat chassis. Five AM mirrors of identical design will be presented: two in aluminium $\left(\mathrm{AlSi}_{10} \mathrm{Mg}\right.$ ), two in nickel phosphorous (NiP) coated $\mathrm{AlSi}_{10} \mathrm{Mg}$, and one in titanium (Ti64). For each material mirror pair, one is hand-polished (including the Ti64) and the other is diamond turned. Metrology data, surface form error and surface roughness, will be presented to compare and contrast the different materials and post-processing methods. To assess the presence of porosity, a frequent concern for AM materials, X-ray computed tomography measurements will be presented to highlight the location and density of pores within the mirror substrate; methods to mitigate the distribution of pores near the optical surface will be described. As a metric for success, the $\mathrm{AlSi}_{10} \mathrm{Mg}+\mathrm{NiP}$ and $\mathrm{AlSi}_{10} \mathrm{Mg}$ mirrors should be suitable in terms of metrology data for visible and infrared applications respectively.
\end{abstract}

Keywords: Additive manufacturing, 3D printing, mirror fabrication, surface roughness, aluminium, titanium, polishing, diamond-turning

\section{INTRODUCTION}

Additive manufacturing (AM; 3D printing) creates a structure additively, layer-upon-layer, as opposed to traditional manufacturing techniques such as: formative (casting, forging), fabricative (cutting, bending, assembly), and, more commonly, subtractive (mill, drill and lathe). ${ }^{1}$ The layer-upon-layer methodology dramatically increases the 'design space' of structures that can be fabricated and the ease and speed by which fabrication occurs. In mirror fabrication, the advantages offered by AM include lightweighting, part consolidation and design optimisations.

Astronomical instrumentation, both ground- and space-based, regularly require low mass per collecting area mirrors within weight constrained systems. Lightweight mirrors to date typically exhibit two designs: ${ }^{2}$ openback structures, where material is either removed from the base (subtractive) or cast in a mould (formative); and sandwich structures, where a lightweight honeycomb core is sandwiched between two face plates (fabricative). To achieve a good optical performance, open-back and sandwich substrates are expensive and time consuming to fabricate - excluding the time taken to generate the optical surface - whereas an AM mirror can be printed and

\footnotetext{
*E-mail: carolyn.atkins@stfc.ac.uk
} 
ready to post-process in a couple of days. Furthermore, the open-back structures exhibit poorer rigidity than sandwich mirrors, but sandwich mirrors are more challenging and expensive to fabricate; ${ }^{3}$ therefore, AM offers the capability to print a sandwich mirror as a single component providing improved rigidity and low cost.

The variety of AM lightweighting options that can be applied to mirror fabrication are incredibly broad. For example, regular and organic styled lattices can be adopted and optimised for function - optimised to minimise the polishing print-through effect (quilting). Part consolidation can be applied to minimise the interfaces between the mirror and the mount, with the potential to reduce distortions upon the optical surface caused by mounting fixtures. In both cases, the restriction in design freedom originates from either the AM geometry guidelines, or the ability to post-process (machine, polish or diamond turn) the printed geometry. However, despite some limitations, AM offers clear benefits in regard to lightweight mirror design and fabrication assuming the required optical quality can be achieved.

AM mirrors is an emerging field with several groups investigating different aspects from mirror fabrication ${ }^{4-7}$ to design optimisation. ${ }^{8-11}$ In regard to mirror fabrication mirror, surface roughness root mean square (Sq; RMS) values of $7.5 \mathrm{~nm}^{7}$ and $22 \mathrm{~nm}$ have been demonstrated on AM aluminium mirrors. Results relating to the roughness values exhibited on AM titanium mirrors are limited; however, two groups have trialled titanium for mirror fabrication. ${ }^{6,7}$ In addition, mirrors have been fabricated using a printed aluminium core, which has been coated in nickel phosphorous (NiP); the aluminium substrate is relatively lightweight and an intricate design can be printed, the NiP adds an ideal material for further processing, an average surface roughness of $1 \mathrm{~nm}$ Sq has been demonstrated ${ }^{5}$ on aluminium $+\mathrm{NiP}$ mirrors.

This paper details the fabrication study which was conducted as part of a UK Space Agency (UKSA) funded project investigating design and fabrication of AM mirrors for CubeSats. The fabrication study investigated the mirror quality that could be obtained on AM substrates through polishing (Pol.) and diamond turning (DT). Five AM mirrors were fabricated as shown in Table 1: four in $\mathrm{AM}$ aluminium $\left(\mathrm{AlSi}_{10} \mathrm{Mg}\right)$ and one in $\mathrm{AM}$ titanium (Ti64), two of the four $\mathrm{AlSi}_{10} \mathrm{Mg}$ mirrors were coated in NiP. The exclusion of a titanium mirror for diamond turning was due to known challenges with the traditional diamond tool shape and the titanium substrate and therefore only two AM mirrors were processed via diamond turning. To provide a benchmark for the diamond turning, a RSA (rapidly solidified aluminium) 6061 blank was also diamond turned.

A single lightweighted design was used for the AM mirrors, based upon a $3 \mathrm{U}$ Earth observation CubeSat, is described in Section 2. A thorough description of the AM mirror design and routes for future design optimisation is given in the sister paper Atkins et al. 2019, ${ }^{12}$ which presents the design study of the UKSA project. The fabrication process chain is presented in Section 3. Metrology data of the internal substrate structure and external metrology data of the optical surface is presented in Section 4.

Table 1. The six mirror variants for fabrication.

\begin{tabular}{|l|l|l|l|l|}
\hline$\#$ & Substrate material & AM fab./ method & Coating & Fabrication method \\
\hline 1 & $\mathrm{AlSi}_{10} \mathrm{Mg}$ & Yes/ L-PBF & NiP & DT \\
2 & $\mathrm{AlSi}_{10} \mathrm{Mg}$ & Yes/ L-PBF & No coating & DT \\
3 & $\mathrm{RSA}^{c} 6061$ & No & No coating & DT \\
4 & $\mathrm{AlSi}_{10} \mathrm{Mg}$ & Yes/ L-PBF & NiP & Pol. \\
5 & $\mathrm{AlSi}_{10} \mathrm{Mg}$ & Yes/L-PBF & No coating & Pol. \\
6 & $\mathrm{Ti} 64$ & Yes/EB-PBF & No coating & Pol. \\
\hline
\end{tabular}

${ }^{a}$ L-PBF - Laser powder bed fusion

${ }^{b} \mathrm{~EB}-\mathrm{PBF}$ - Electron beam powder bed fusion

${ }^{c}$ RSA - Rapidly solidified aluminium

\section{SPECIFICATION OF THE MIRROR DESIGN}

A thorough description of the mirror design and design logic is presented in the sister paper Atkins et al. $2019 ;^{12}$ therefore, only a summary is presented within this section. 


\subsection{Mirror requirements}

The AM mirror requirements were based upon the primary mirror in a $1.2 \mathrm{U}(1 \mathrm{U}=100 \mathrm{~mm} \times 100 \mathrm{~mm} \times 100 \mathrm{~mm})$ Cassegrain telescope configuration designed for a $3 \mathrm{U}$ CubeSat paper study - CubeSat Camera (CCAM). ${ }^{13}$ The requirements are presented in Table 2. The optical prescription of the telescope has been simplified to a spherical concave form to facilitate fabrication and metrology of the mirror surface. Further to the requirements in Table 2, a lightweight lattice structure was desired for the internal volume of the mirror to demonstrate one of the design benefits of AM.

To judge the success of the mirror fabrication, the optical surfaces are assessed against the AM mirror success criteria detailed in Table 3. These criteria define the optical surface in terms of surface form error, peak to valley $(\mathrm{PV})$ and RMS, and the surface roughness RMS. Due to the heritage of NiP coated mirrors, the $\mathrm{AlSi}_{10} \mathrm{Mg}+$ $\mathrm{NiP}$ mirrors are expected to demonstrate a better optical surface than the $\mathrm{AlSi}_{10} \mathrm{Mg}$ mirrors and therefore the two mirror variants are assessed against the visible and infrared criteria respectively. With limited knowledge in regard to the Ti64 substrate, there is no expectation on the achievable performance.

Table 2. AM mirror design requirements

\begin{tabular}{|l|l|}
\hline Property & Value \\
\hline Optical prescription & Spherical, concave \\
Radius of curvature & $350 \mathrm{~mm}$ \\
Clear aperture diameter & $80 \mathrm{~mm} \varnothing$ \\
Mechanical diameter & $84 \mathrm{~mm} \varnothing$ \\
Total height & $17.3 \mathrm{~mm}$ \\
Mounting features & $3 \times \mathrm{M} 3$ holes \\
Fiducials & A notch every $45^{\circ}$ \\
Lightweighting & Internal lattice structure \\
\hline
\end{tabular}

Table 3. AM mirror success criteria
\begin{tabular}{|l|l|l|l|}
\hline \multirow{2}{*}{ Wavelength range } & \multicolumn{2}{|c|}{ Surface form error } & Surface roughness \\
\cline { 2 - 4 } & PV $[\mathrm{nm}]$ & RMS $[\mathrm{nm}]$ & RMS $[\mathrm{nm}]$ \\
\hline Visible $\lambda: 400 \mathrm{~nm}$ to $700 \mathrm{~nm}$ & $<150$ & $<45$ & $<5$ \\
Infrared $\lambda: 1000 \mathrm{~nm}$ to $1500 \mathrm{~nm}$ & $<300$ & $<90$ & $<12$ \\
\hline
\end{tabular}

\subsection{The AM mirror design}

There are two designs required in the fabrication of the AM mirror: a design for printing and a design after machining. The requirements in Table 2 represent the dimensions after machining and therefore the design for printing is an oversized version of these dimensions with additional features to aid machining. The oversizing of the substrate is required in order to accommodate the material that will be removed from the surface through machining - metal powder bed fusion processes typically result in a rough surface. Figure 1 a) presents the functional mirror component, i.e. the design after machining. Figures $1 \mathrm{~b}$ ) and c) demonstrate the design for printing and highlight a sacrificial spigot used to facilitate machining. The holes on the base of the mirror (Figure $1 \mathrm{~b})$ ) allow removal of the unsintered metallic powder from the lightweighted cavity. The lightweighting structure is a body centred cubic (BCC) lattice within an ellipsoidal cavity (Figure $1 \mathrm{c}$ ))

\subsection{Finite element analysis: print-through estimate}

One of the challenges of lightweight mirrors is the imprinting of the lightweight structure upon the optical structure due to the non-uniform support, as shown in Figure 2. Finite element analysis (FEA) was used to predict the form of the distortions that might be expected after diamond turning or polishing. COMSOL Multiphysics was used to perform the simulation and the design-after-machining was used as the input CAD 


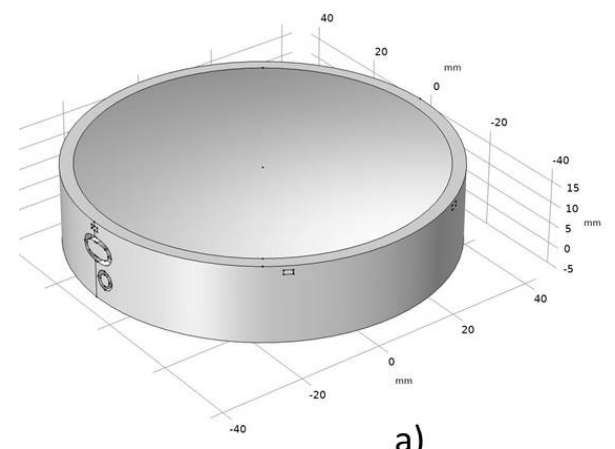

a)
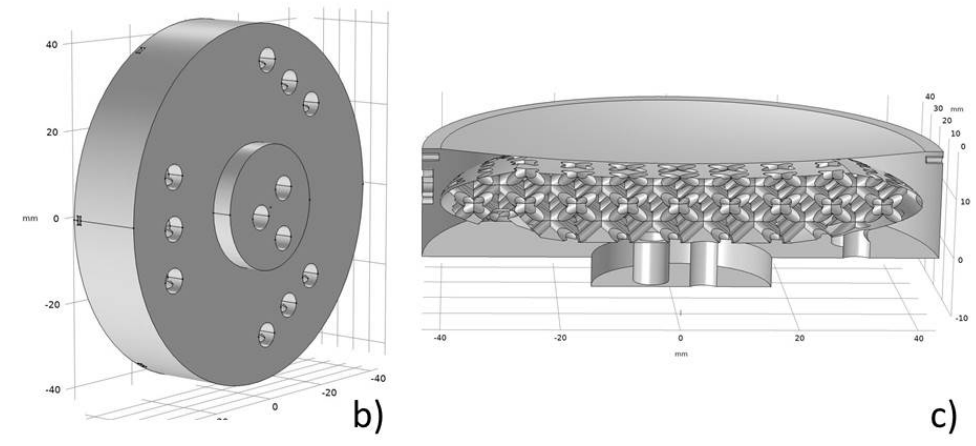

c)

Figure 1. The AM design to print: a) the mirror surface and fiducials after machining; b) the base of the AM design with the holes for powder removal and a spigot to aid machining; and c) the internal geometry of the AM design demonstrating an internal ellipsoidal cavity populated with a BCC lattice.

file. Polishing and diamond turning apply forces over significantly different areas, a polishing pad might have the same dimensions as the mirror, whereas the diamond tool radius is typically $1 \mathrm{~mm}$ to $2 \mathrm{~mm}$. The physical boundary conditions - how the substrate is mounted - also vary between the two methods, in polishing the substrate is loosely held, whereas the substrate is rigidly held for diamond turning. Therefore the FEA has been used as indicative tool to suggest the form of the error that might be observed after processing, as opposed to using the values of displacement in absolute terms.

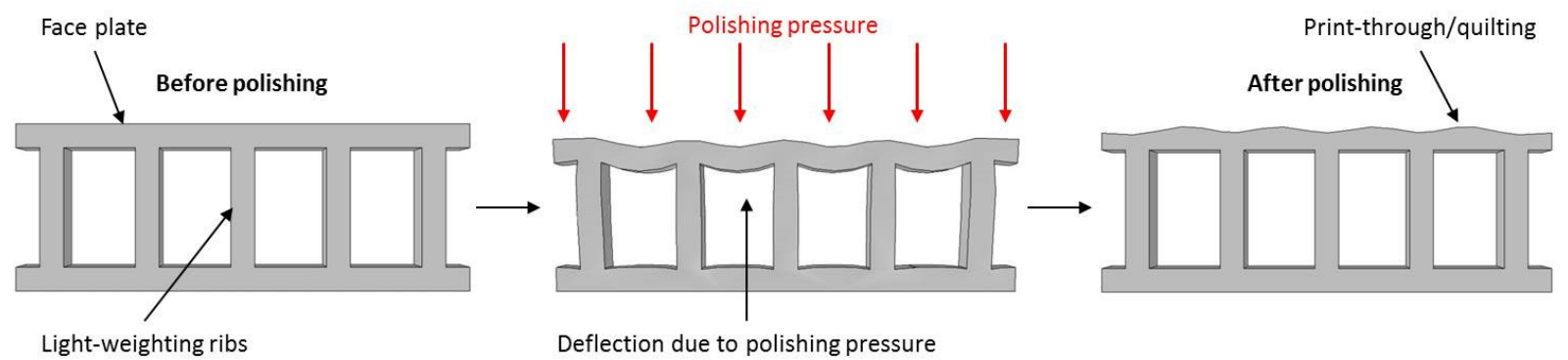

Figure 2. An illustration of the polishing print-through effect (quilting) caused by a non-uniform support below the mirror surface.

Figure 3 a) highlights the boundary conditions applied to the FEA model: the part is centred at $(0,0,0)$; the base is fixed in $\mathrm{z}$; the edges from $z=0 \longrightarrow$ mirror height at $x=0$ an $y=0$ are partially fixed to allow displacement along the axes, but to prevent twisting; and a uniform polishing pressure of $3500 \mathrm{~N} / \mathrm{m}^{2}$ is applied along the negative $\mathrm{z}$ direction. Figure $3 \mathrm{~b}$ ) left is the predicted form error on the application of the polishing pressure, the lightweighted core causes a sag in the centre of the mirror. Figure 3 b) right presents the expected displacement after subtraction of the first four Zernike terms (piston, tiltx, tilty and focus; Z0 - Z3) and provides an indication of the form error that might be expected during interferometric testing.

\section{MIRROR FABRICATION}

Table 1 presented the six mirror variants for fabrication; each AM mirror is identical in design, but is unique in fabrication route. Figure 4 presents the fabrication process chain from mirror design to the generation of the optical surface for each of the five AM mirrors. The RSA 6061 mirror was fabricated via a traditional subtractive machining from block material and therefore is not included in detail within the fabrication chain. 


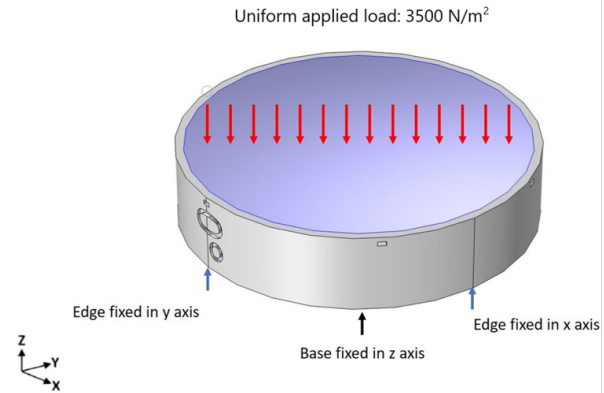

a)
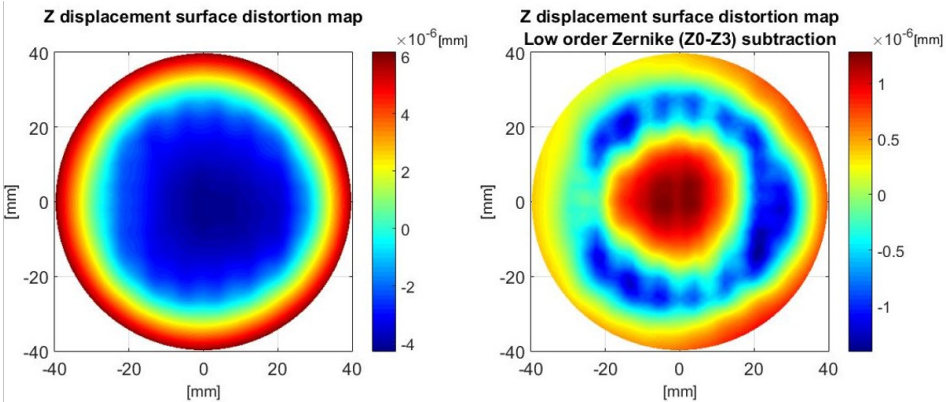

b)

Figure 3. a) the boundary conditions applied within the FEA model; b) left the predicted distortion of the optical surface upon application of pressure; and b) right the expected distortion after subtraction of the first four Zernike terms (Z0-Z3) and is an estimate of the form error observed during interferometric testing.

\subsection{Additive manufacture}

The additive manufacture of the aluminium and titanium substrates was undertaken at CA Models Ltd and University of Sheffield respectively. In both cases the substrates were created via powder bed fusion (PBF), where fine metal powder is either fused together by a laser (L-PBF) or an electron beam (EB-PBF).

\subsubsection{The aluminium substrates}

The aluminium substrates were printed in the alloy $\mathrm{AlSi}_{10} \mathrm{Mg}$, which is commonly used in $\mathrm{AM}$. The substrates were printed on a SLM 500HL by CA Models Ltd, which has a $500 \mathrm{~mm} \times 280 \mathrm{~mm} \times 365 \mathrm{~mm}$ build volume and $4 \times 400 \mathrm{~W}$ lasers operating simultaneously.

The four substrates were built in the vertical orientation, as shown in Figure 5, with external support material added to the substrates to provide both support and heat dissipation - a thorough description concerning build orientation selection can be found in Atkins et al. 2019. ${ }^{12}$ Following build completion the excess powder was removed and the substrates were thermally cycled before separation from the build plate to relieve stress within the build. In the final stage, the support material was removed from the substrate - tooling marks in Figure 5 right highlight where the support material has been removed around the spigot.

\subsubsection{The titanium substrate}

The titanium substrates were printed at the University of Sheffield using an ARCAM Q20+, which is an EB-PBF AM machine. The Q20+ has a cylindrical build volume with $350 \mathrm{~mm}$ diameter and $380 \mathrm{~mm}$ height. The titanium alloy used for the substrates was Ti-6Al-4V, commonly known as Ti64.

The titanium substrates, like the aluminium substrates, were built in the vertical orientation as shown in Figure 6. Following completion of the build, excess powder was removed and the substrates separated from the build plate. Due to the elevated temperature of the EB-PBF over the L-PBF during build, no additional thermal cycling was required once the build was complete to relieve stress.

\subsection{Traditional machining}

The aluminium and titanium substrates were subtractively machined at the RAL Space Precision Development Facility. The spigot shown in Figure $1 \mathrm{~b}$ ) was used to hold the substrates for machining of the side walls and the concave mirror surface, the spigot was then removed when the base of the substrate was machined. Upon the completion of the traditional machining, the substrates were split into those intended for polishing and those for diamond turning. 


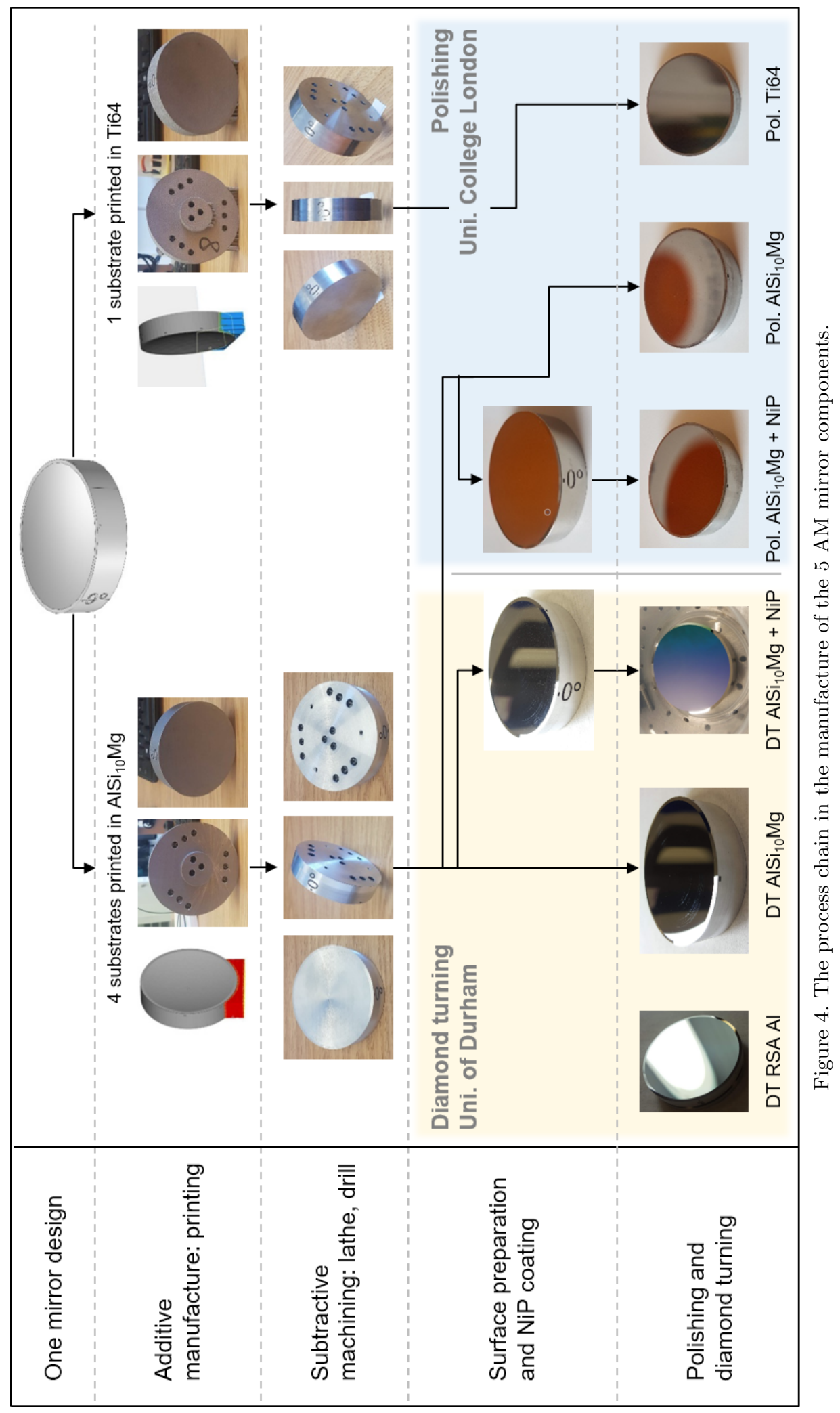

Proc. of SPIE Vol. 11116 1111616-6 

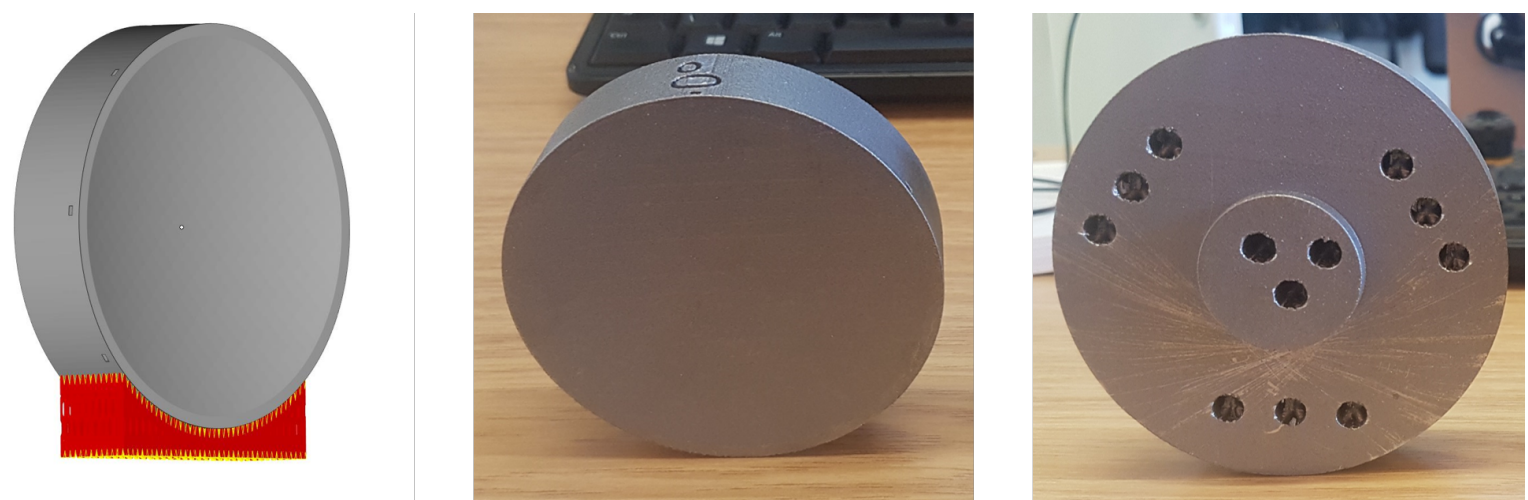

Figure 5. The additive manufacture of the aluminium substrates: left - the design with the AM set-up software where the orientation and the support material (red) is defined; middle and right - the aluminium substrates after printing and with support removal.
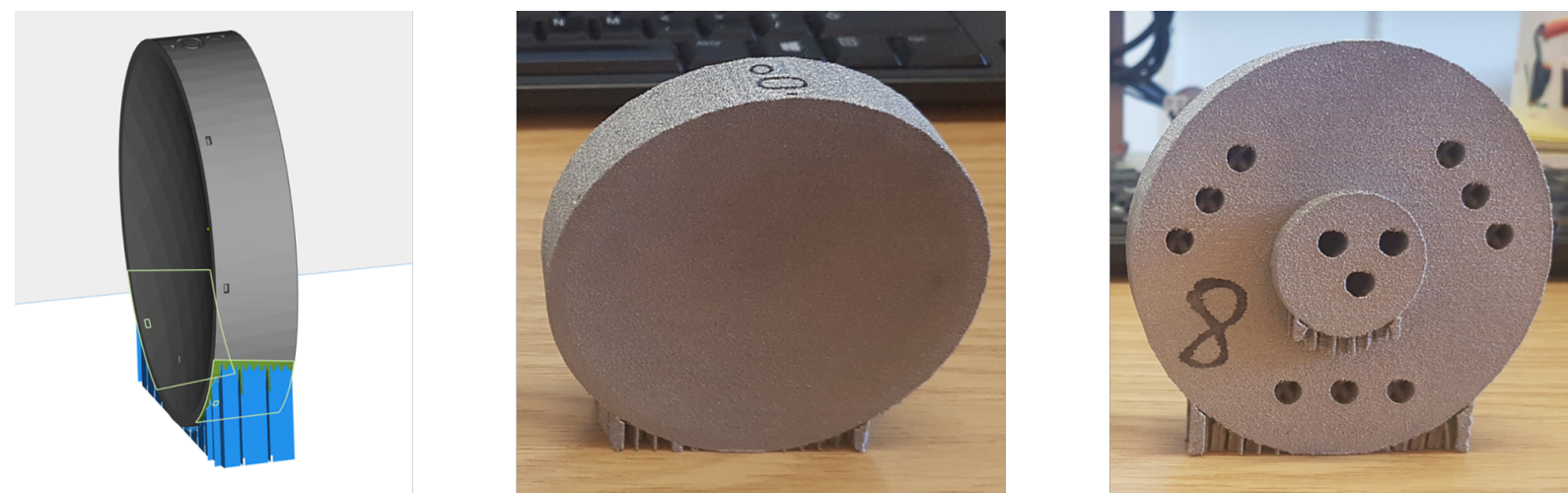

Figure 6. The additive manufacture of the titanium substrates: left - the design with the AM set-up software where the orientation and the support material (blue) is defined; middle and right - the titanium substrates after printing, the support material can be observed on the spigot and on the mirror side wall which is in contact with the build platform. 


\subsection{Polishing}

Traditional hand-polishing was undertaken at University College London to generate the optical surfaces on the $\mathrm{AlSi}_{10} \mathrm{Mg}, \mathrm{AlSi}_{10} \mathrm{Mg}+\mathrm{NiP}$ and Ti64 substrates. First, the machined substrates were centred upon a $300 \mathrm{~mm}$ diameter polishing machine and supported with three Neoprene faced clamps. SiC 220 grit was used to fine grind the substrates using a Perspex or aluminium tool for the $\mathrm{AlSi}_{10} \mathrm{Mg}$ and Ti64 substrates respectively. Upon the removal of the machining mark, successively finer $\mathrm{SiC}$ grades were used to converge the surface to $<2 \mu \mathrm{m}$ PV from error after best fit radius of curvature subtraction and within $1 \mathrm{~mm}$ of the desired radius of curvature $(350 \mathrm{~mm})$. Upon completion of the fine grinding, one of the $\mathrm{AlSi}_{10} \mathrm{Mg}$ substrates was coated with $100 \mu \mathrm{m}$ of $\mathrm{NiP}$ and then reground to remove surface imperfections (bubbles, inclusions) within the NiP layer.

The $\mathrm{AlSi}_{10} \mathrm{Mg}$ and $\mathrm{AlSi}_{10} \mathrm{Mg}+\mathrm{NiP}$ substrates were initially prepolished using $3 \mu \mathrm{m}$ grade aluminium oxide (Alox) combined with a high quality polishing cloth, the resultant surface form error could be measured using the interferometer $(\lambda=633 \mathrm{~nm})$. The $\mathrm{AlSi}_{10} \mathrm{Mg}+\mathrm{NiP}$ sample was further refined using a $70 \mathrm{~mm}$ diameter pitch tool with $1 \mu \mathrm{m}$ grade Alox. The $\mathrm{AlSi}_{10} \mathrm{Mg}$ sample proved challenging due to significant pin-holes and scratches and therefore the substrate did not progress beyond the $3 \mu \mathrm{m}$ grade of Alox. The polishing procedure of the Ti64 substrate is proprietary; however, a factor of three increase in the polishing pressure of the aluminium substrates was applied to obtain the optical surface.

\subsection{Diamond turning}

Single point diamond turning is a widely used machining technique which consists of cutting material with a diamond tool using a purposely built ultra-high precision turning machine. While the part is rotating, the tool moves axially (z-axis) and transversally (x-axis) relative to the axis of rotation, cutting the desired shape (Figure 7). By synchronizing the angular position of the part (c-axis) with both $\mathrm{x}$ and $\mathrm{z}$ axes, the machine can cut non-rotationally symmetrical parts (freeform surfaces), with large sag and steep slope. In the case of the AM substrates, which have a rotationally symmetrical profile (on axis spheres), only 2 axes were required ( $\mathrm{z} \& \mathrm{x}$ ).

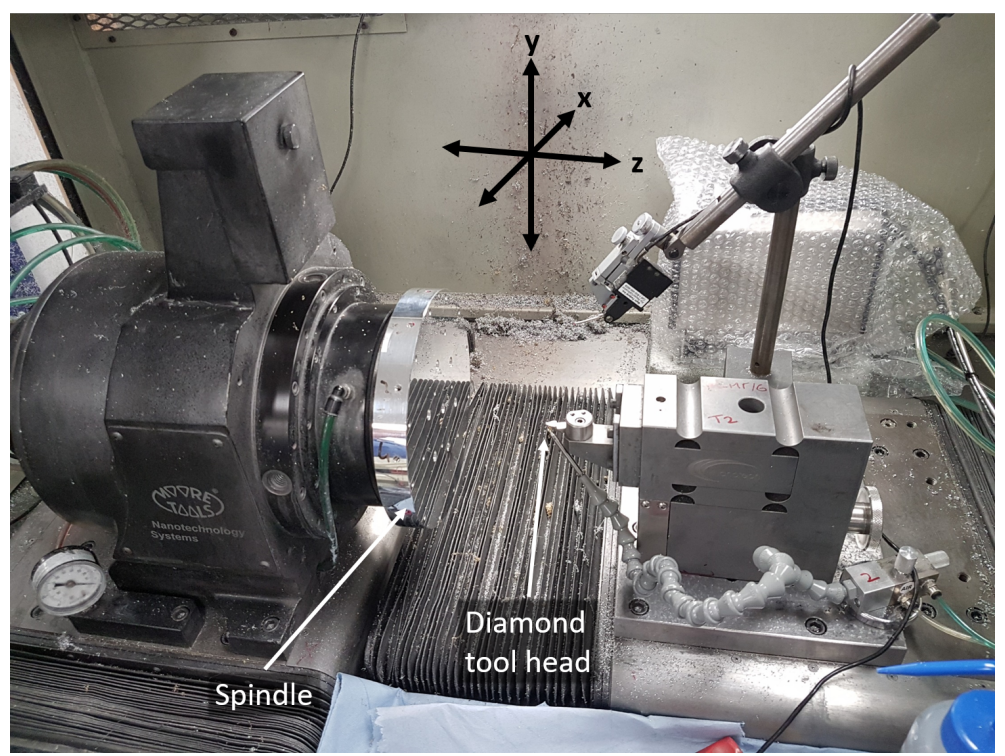

Figure 7. The Moore Nanotech UPL diamond turning machining at Durham University.

The two $\mathrm{AlSi}_{10} \mathrm{Mg}$ substrates and the RSA 6061 blank were machined at the Centre for Advanced Instrumentation, at Durham University, using a Moore Nanotech 250 UPL machine. The diamond machining of the $\mathrm{AlSi}_{10} \mathrm{Mg}$ substrates did not involve any bespoke set-up, tooling or machining parameters; the process for diamond turning of conventional aluminium (RSA 6061) was employed. The substrates were all cut with a diamond tool radius of $1.5 \mathrm{~mm}$ at $2000 \mathrm{RPM}$ with a feedrate of $10 \mathrm{~mm} / \mathrm{min}$. 
The two $\mathrm{AlSi}_{10} \mathrm{Mg}$ substrates machined well although the surface cosmetic was not as good as for the RSA 6061 blank. In particular, pickup marks (scratches on average $1.5 \mu \mathrm{m}$ wide, $200 \mathrm{~nm}$ deep) and holes (digs approx. $10 \mu \mathrm{m}$ to $20 \mu \mathrm{m}$ diameter and $15 \mu \mathrm{m}$ deep, due to the porosity of the AM material) were visible. The $\mathrm{AlSi}{ }_{10} \mathrm{Mg}$ substrate that exhibited the worst optical surface was sent for $100 \mu \mathrm{m}$ of NiP coating and then diamond turned again to achieve the desire optical prescription.

\section{METROLOGY}

Internal and external metrology was performed within this project. Internal structure of the AM substrates was evaluated using X-ray computer tomography $(\mathrm{XCT})$, while the external mirror surface was quantified in terms of surface form error and surface roughness via an interferometer $(\lambda=633 \mathrm{~nm})$ and a microscope interferometer respectively. During diamond turning and polishing, metrology data was taken to ensure the optical surface converged to the desired optical prescription; however, to remove systematic variations between metrology equipment, mounting and measurement environment, all six mirrors were measured at UK Astronomy Technology Centre (UKATC) for surface form error and at the Diamond Light Source (DLS) for surface roughness.

\subsection{X-ray computer tomography}

The measurements were undertaken and analysed at the National Physical Laboratory (NPL) using a micro XCT scanner which resulted in a 3D data map with a pixel size of $57 \mu \mathrm{m}$. Cross sections of the aluminium substrate are shown in Figure 8 and the fine pixel resolution of the data allowed the porosity within the AM substrate to be quantified. It should be noted that the XCT measurements were not performed on the substrates that were processed into mirrors, but rather on spare $\mathrm{AlSi}_{10} \mathrm{Mg}$ and Ti64 substrates that were available. Due to uncertainty in the titanium XCT results, only the $\mathrm{AlSi}_{10} \mathrm{Mg} \mathrm{XCT}$ analysis is discussed in this section.

In AM mirror fabrication, the primary concern relating to the AM substrate is porosity within the reflecting surface which leads to increased scatter. Therefore, the analysis performed at NPL explored the skin of mirror surface and quantified the number of pores within its $2 \mathrm{~mm}$ thickness. A description of the analysis procedure is discussed within P. Cooper et al. 2019. ${ }^{14}$ Figure 9 presents the results of the porosity study - the pores were identified and counted in the plane normal to the optical surface. The curvature of the mirror surface was removed within software for simplicity, as shown in Figure 9 left. The number of pores within the $2 \mathrm{~mm}$ thick skin were counted and Figure 9 right highlights the number of the pores as a percentage of the substrate as a function of depth below the mirror surface for the $\mathrm{ALSi}_{10} \mathrm{Mg}$ substrate. The results demonstrate that there is a significant increase in porosity at approx. $0.5 \mathrm{~mm}$ below the surface of the substrate. It is suspected that this increase in porosity is an effect of an interface between two AM machine settings, where the perimeter of the part is printed first and then the internal structure is filled-in. This result is a concern for AM mirror fabrication, it suggests that the material that is removed through traditional machining and polishing/ diamond turning $(0.25 \mathrm{~mm}$ to $1.00 \mathrm{~mm}$ depth) would place the optical surface within the porous layer of the AM substrate, leading to an increase in surface roughness.

Despite the fact that the substrate evaluated was not used in fabrication, there is confidence that similar porosity effects would be seen in the processed substrates if the porosity is a systematic effect caused by the AM machine properties. Unfortunately, in this project, due to the rapid turn-around, the XCT data was unable to influence our fabrication process chain to avoid the porosity layer in the aluminium substrates. However, manipulation of porosity within a build is an active area study and there are routes that could be applied in the future to minimise the pores in the critical regions for mirror fabrication. ${ }^{15}$ Therefore with an ability to manipulate porosity and to quantify both location and number density, optimum AM material properties can be defined in the location of the optical surface in the future.

\subsection{Surface form error}

The surface form error of the optical surfaces were measured at the UKATC using a Zygo Dynafiz $(\lambda=633 \mathrm{~nm})$. For measurement, the mirrors were mounted via an interface plate to a tip tilt stage using the three threaded holes in the mirror base. Minimal force was applied to the screws to prevent mounting distortions upon the optical surface. Figure 10 presents the six interferograms depicting the surface form error after subtraction of the first four Zernike terms. For each interferogram, the PV, PVr (robust peak to valley) and the RMS were 


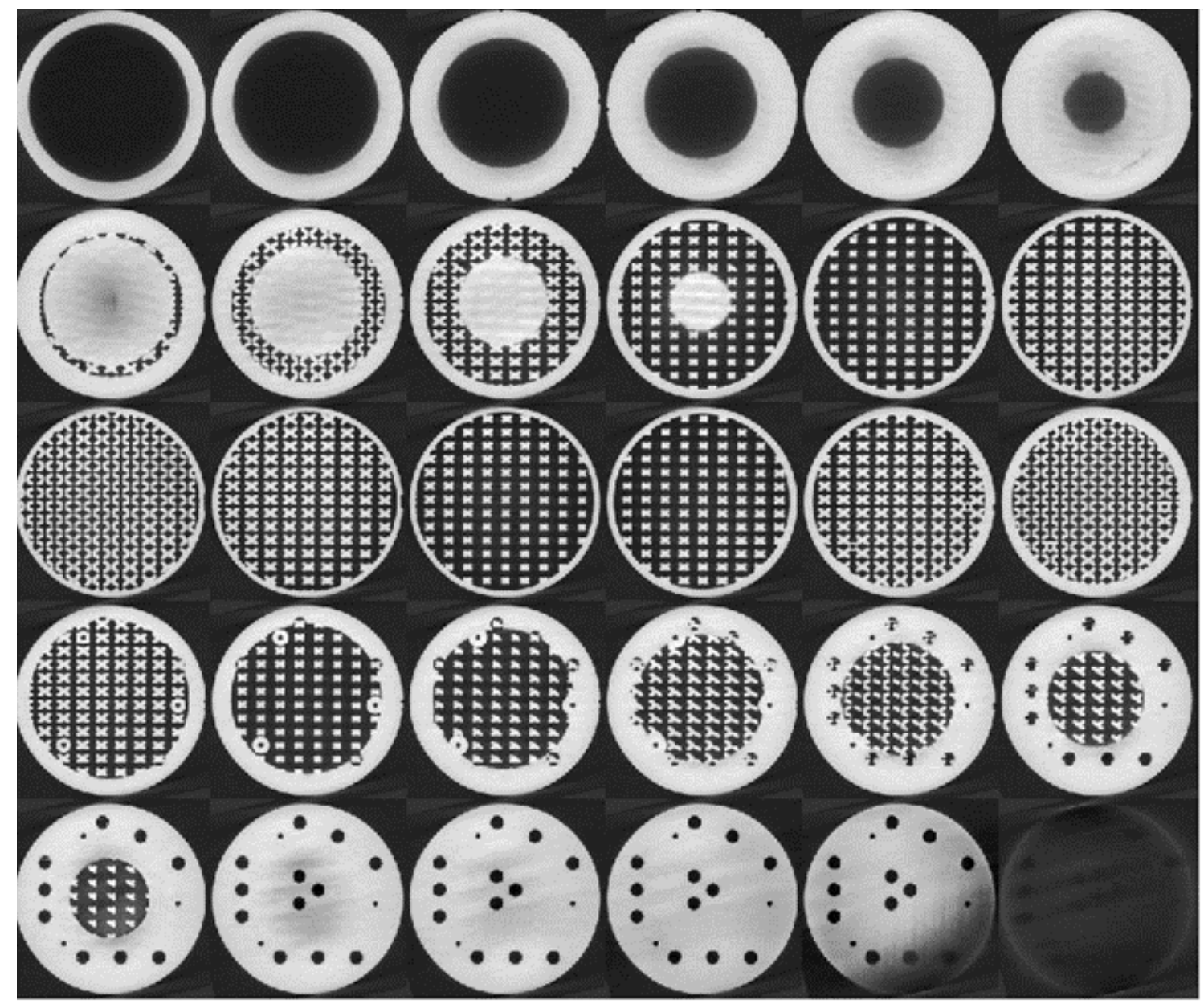

Figure 8. XCT slices through the aluminium substrate; the cross section on the top left is the concave surface of the substrate and the bottom right image is the flat base of the substrate. Credit: NPL
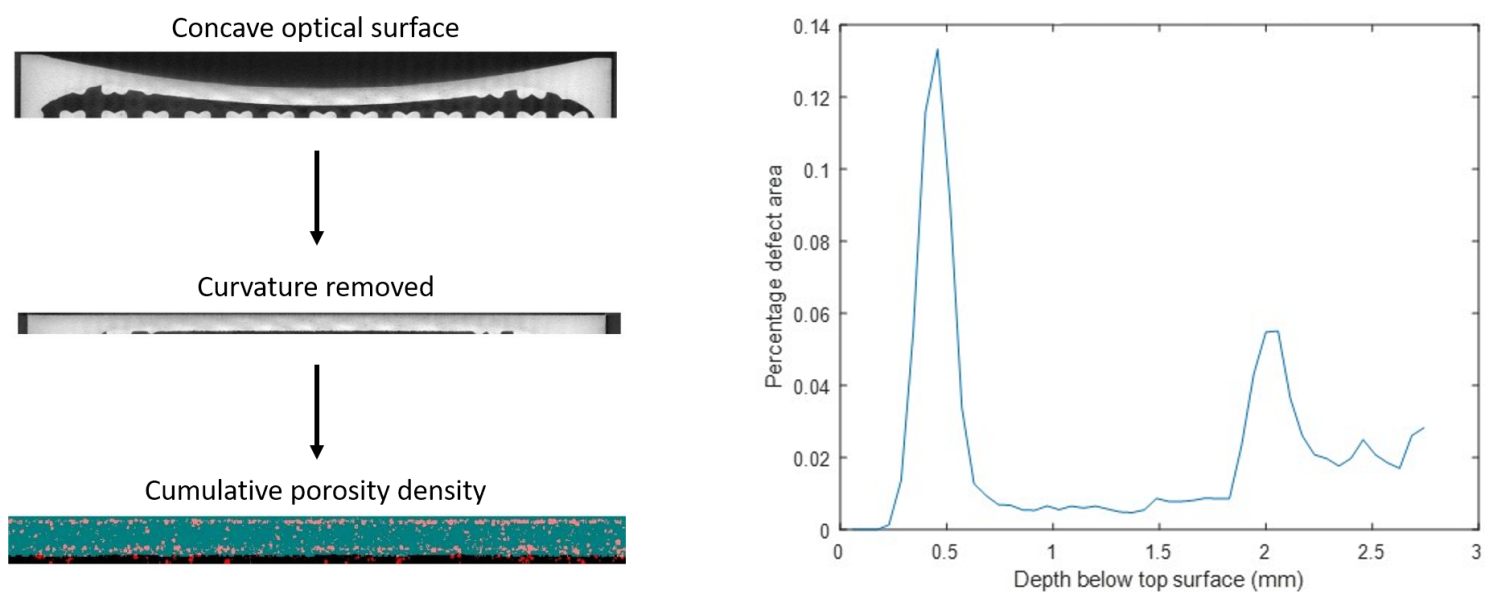

Figure 9. Analysis of the XCT data from the aluminium substrate: left - simplification of the substrate form to facilitate the calculation of porosity; right - the cumulative porosity in the mirror skin as a function of skin depth. Credit: NPL 
recorded (Table 4). The difference between the PV and the PVr is that the PV is an absolute max - min range, which is prone to misrepresentation of the mirror surface due to localised defects (dust, pits), whereas the $\mathrm{PVr}$ is the PV of a fitted surface which is not sensitive to localised defects.

\subsubsection{Surface form error analysis}

The majority of the mirror surfaces, excepting Pol. AlSi ${ }_{10} \mathrm{Mg}$, demonstrate a PVr between $127 \mathrm{~nm}$ to $295 \mathrm{~nm}$ and an RMS between $25 \mathrm{~nm}$ to $35 \mathrm{~nm}$, which was within the desired operation wavelengths of visible to IR (Table 3). In addition, the shape of the surface form error in all except the DT $\mathrm{AlSi}_{10} \mathrm{Mg}$ and DT RSA6061, is similar to that predicted via the FEA (Figure 3) - highlighting the non-uniform support of the mirror surface. Ripples were observed in the $\mathrm{DT} \mathrm{AlSi}_{10} \mathrm{Mg}+\mathrm{NiP}$ mirror, the origin of these ripples remains unclear, but it is suspected that they could either be an effect due to vibration/ fringing, or that a temperature change has resulted in the differential expansion of the $\mathrm{AlSi}_{10} \mathrm{Mg}$ substrate and the $\mathrm{NiP}$ coating causing an imprint of the lightweight structure upon the mirror surface - further analysis is required.

In regard to the Pol. $\mathrm{AlSi}_{10} \mathrm{Mg}$ mirror, the surface form error is clearly poor in comparison the other mirrors. Polishing of the $\mathrm{AlSi}_{10} \mathrm{Mg}$ mirror proved challenging, initial results exhibited a large number of pits and scratches, which required the sample to be reground and repolished several times. Unfortunately, as demonstrated in the $\mathrm{XCT}$ data (Section 4.1), if polishing was taking place in the porous layer, which is suspected, then reworking the surface would not remove the necessary thickness to reach the denser AM material. Therefore the Pol. $\mathrm{AlSi}_{10} \mathrm{Mg}$ was unable to achieve an equivalent performance than that of the DT $\mathrm{AlSi}_{10} \mathrm{Mg}$ without a significant reworking, which was beyond the time frame of the project.

Table 4. Collation of form error measurements taken at UKATC on the Zygo Dynafiz

\begin{tabular}{|c|l|l|l|l|}
\hline \multicolumn{5}{|c|}{ Surface form error measurements } \\
\hline$\#$ & Mirror & PV [nm] & PVr [nm] & RMS [nm] \\
\hline 1 & DT AlSi ${ }_{10} \mathrm{Mg}+\mathrm{NiP}$ & 177 & 150 & 30 \\
2 & DT AlSi ${ }_{10} \mathrm{Mg}$ & 231 & 154 & 28 \\
3 & DT RSA 6061 & 152 & 127 & 25 \\
4 & Pol. AlSi ${ }_{10} \mathrm{Mg}+\mathrm{NiP}$ & 271 & 204 & 35 \\
5 & Pol. AlSi ${ }_{10} \mathrm{Mg}$ & 593 & 474 & 83 \\
6 & Pol. Ti64 & 225 & 295 & 28 \\
\hline
\end{tabular}

\subsection{Surface roughness measurements}

The surface roughness measurements were undertaken at the Diamond Light Source (DLS) using a Bruker Contour GT-X stitching microinterferometer. A $3 \times 3$ grid of individual measurements was centred upon the mirror with $25 \mathrm{~mm}$ spacing between each sample area; however, due to the curvature of the mirror and the size of the microscope head, only 6 out 9 measurements could be performed. The measurements were numbered $1 \longrightarrow 9$, with the upper left grid sample designated 1 and the bottom right grid sample designated 9. Each mirror was orientated with $0^{\circ}$ facing the operator and secured using 4 clamps. A $10 \times$ microscope objective was used for the measurements, resulting in a sample area of approx. $0.6 \mathrm{~mm}$ by $0.45 \mathrm{~mm}$. Due to time restrictions only the diamond turned mirrors have been measured to date: DT AlSi ${ }_{10} \mathrm{Mg}+\mathrm{NiP}, \mathrm{DT}$ AlSi ${ }_{10} \mathrm{Mg}$ and DT RSA 6061 are presented in Figures 11, 12 and 13 respectively.

\subsubsection{Analysis of the surface roughness measurements}

The mean of the average roughness (Sa), the RMS roughness (Sq) and the PV roughness (Sz) values for the 6 measurements on each DT AM mirrors are presented in Table 5. The low order spatial frequency terms that have been removed from the data sets are: piston, tilt $\mathrm{x}$, tilt $\mathrm{y}$ and curvature. Loss of data is represented as white pixels and is not included in the calculation of the roughness terms - loss of data is particularly evident in DT AlSi ${ }_{10} \mathrm{Mg}$ data (Figure 12). 


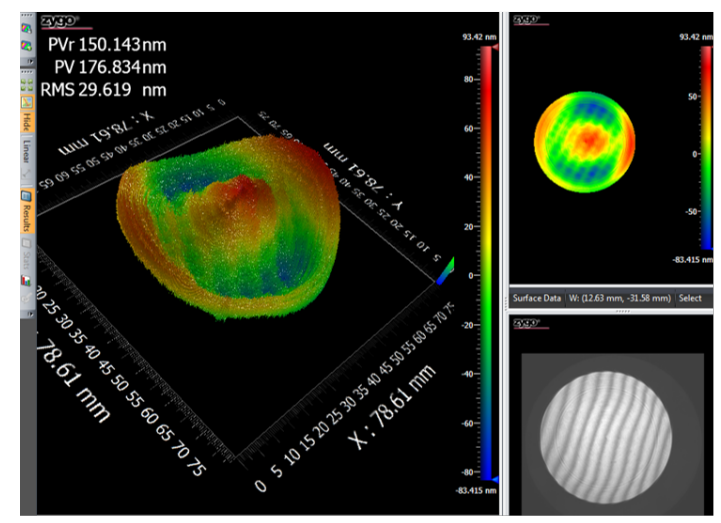

DT: $\mathrm{AlSi}_{10} \mathrm{Mg}+\mathrm{NiP}$

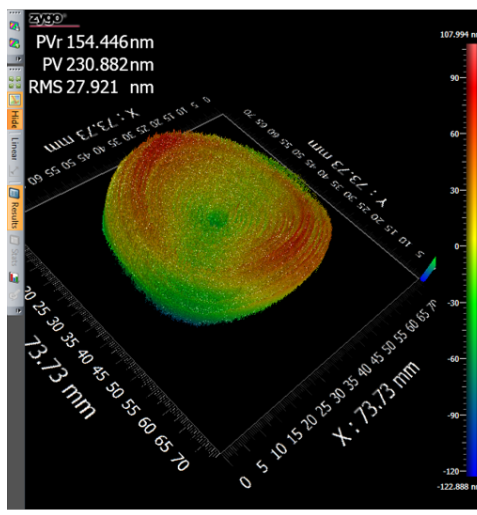

DT: $\mathrm{AlSi}_{10} \mathrm{Mg}$

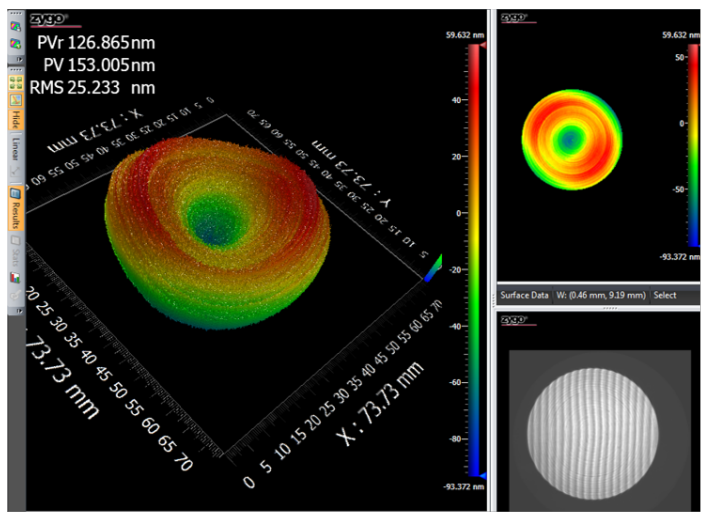

DT: RSA 6061

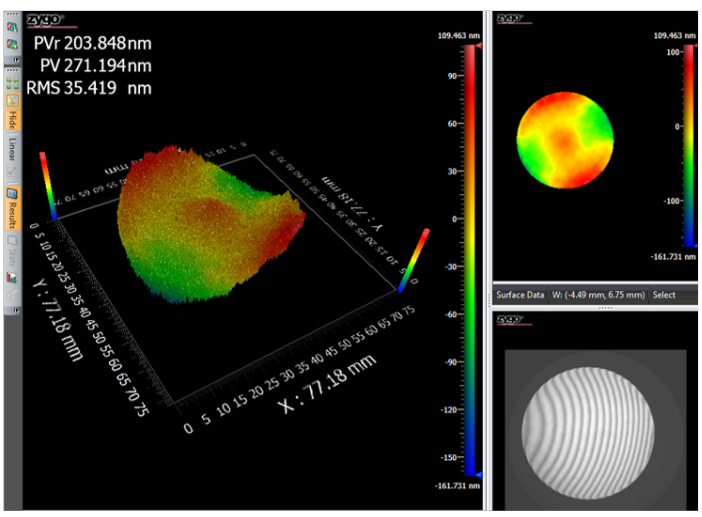

Pol.: $\mathrm{AlSi}_{10} \mathrm{Mg}+\mathrm{NiP}$

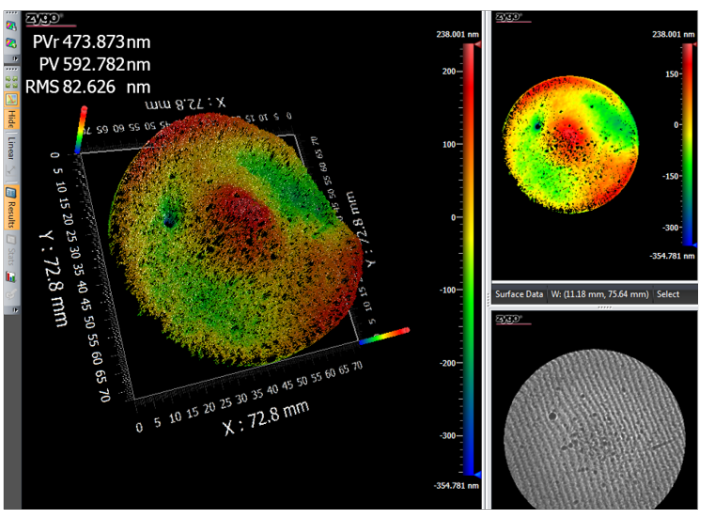

Pol.: $\mathrm{AlSi}_{10} \mathrm{Mg}$

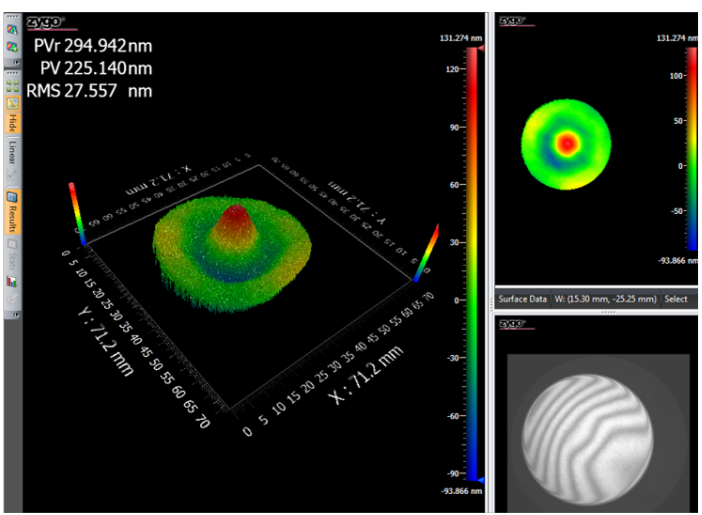

Pol.: Ti64

Figure 10. The surface form error of the six mirrors upon subtraction of the first four Zernike terms (Z0 - Z3): top $\mathrm{AlSi}_{10} \mathrm{Mg}+\mathrm{NiP}$ mirrors; middle - $\mathrm{AlSi}_{10} \mathrm{Mg}$ mirrors; and bottom DT RSA 6061 (left), Pol. Ti64 (right). 
1

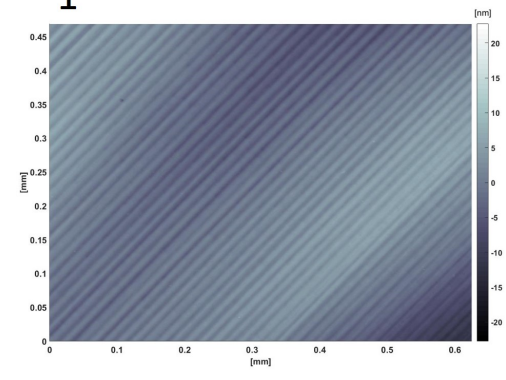

DT: $A l \mathrm{Si}_{10} \mathrm{Mg}+\mathrm{NiP}$

\section{0x magnification}

Measurement area: $\sim 0.6 \mathrm{~mm} \times \sim 0.45 \mathrm{~mm}$
2

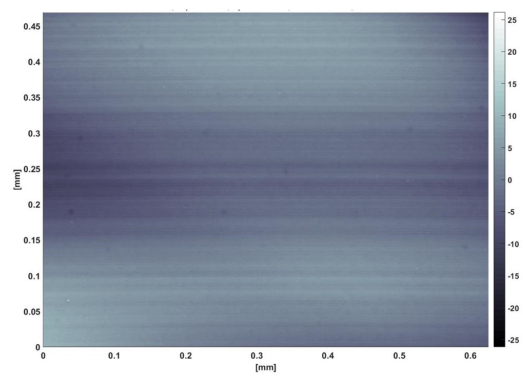

5

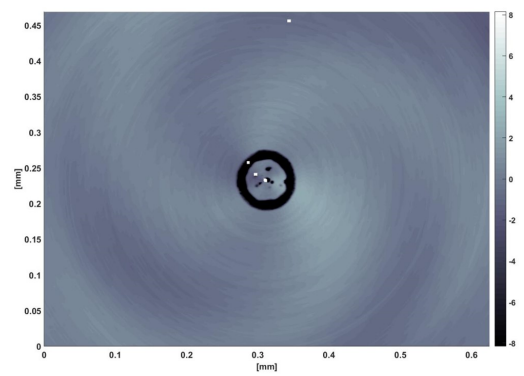

6

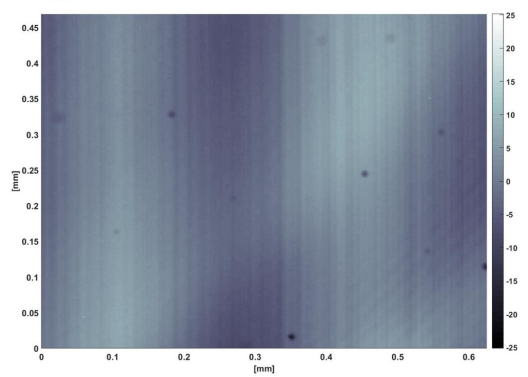

9
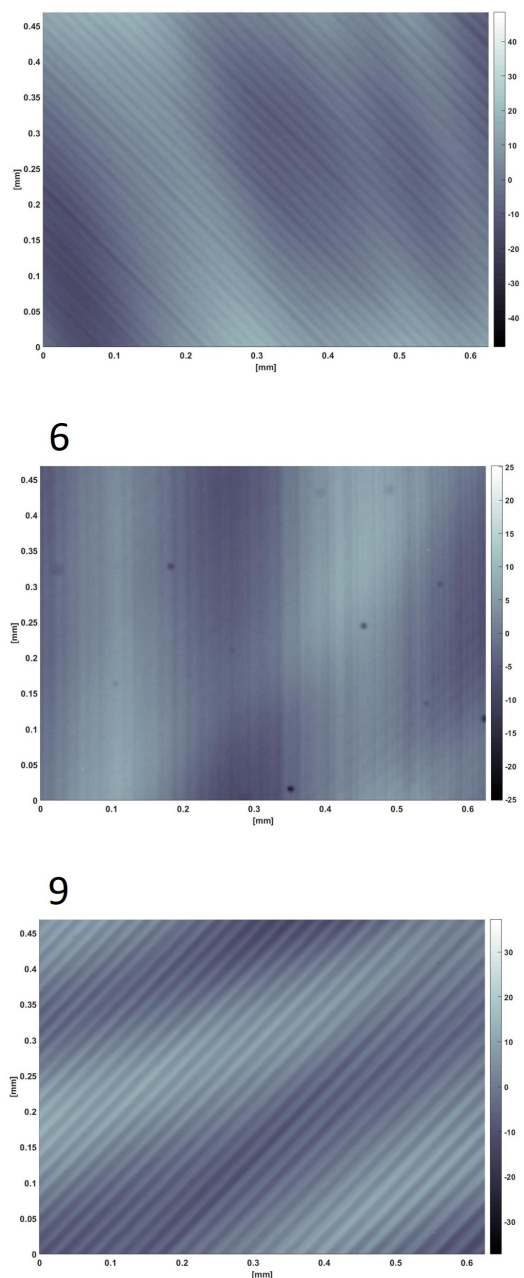

DT: AlSi10Mg + NiP

\begin{tabular}{|l|l|l|l|l|l|}
\hline$\#$ & Sa [nm] & Sq [nm] & Sp [nm] & Sv [nm] & Sz [nm] \\
\hline
\end{tabular}

\begin{tabular}{|r|r|r|r|r|r|}
\hline 1 & 2.62 & 3.25 & 7.64 & -12.93 & 20.57 \\
\hline 2 & 3.50 & 4.16 & 22.03 & -12.85 & 34.88 \\
\hline 3 & 6.34 & 7.72 & 20.72 & -19.57 & 40.28 \\
\hline 5 & 4.89 & 9.42 & 20.40 & -193.00 & 213.00 \\
\hline 6 & 3.36 & 4.00 & 10.84 & -21.04 & 31.89 \\
\hline 9 & 4.47 & 5.31 & 13.97 & -14.25 & 28.22 \\
\hline \multicolumn{7}{|c|}{} & & & \\
\hline Average & $\mathbf{4 . 2 0}$ & $\mathbf{5 . 6 4}$ & $\mathbf{1 5 . 9 3}$ & $-\mathbf{4 5 . 6 1}$ & $\mathbf{6 1 . 4 7}$ \\
\hline
\end{tabular}

Figure 11. The surface roughness measurements of the DT $\mathrm{AlSi}_{10} \mathrm{Mg}+\mathrm{NiP}$ mirror.

Table 5. Surface roughness of the AM mirrors; an average of 6 measurements

\begin{tabular}{|l|l|l|l|l|}
\hline \multicolumn{5}{|c|}{ Surface roughness } \\
\hline$\#$ & Mirror & $\mathrm{Sa}[\mathrm{nm}]$ & $\mathrm{Sq}[\mathrm{nm}]$ & $\mathrm{Sz}[\mathrm{nm}]$ \\
\hline 1 & DT AlSi $_{10} \mathrm{Mg}+\mathrm{NiP}$ & 4.20 & 5.64 & 61.47 \\
2 & DT AlSi $_{10} \mathrm{Mg}$ & 3.59 & 4.85 & 192.90 \\
3 & DT RSA $6061_{4}$ & 3.74 & 4.96 & 160.42 \\
4 & ${ }^{d}$ Pol. AlSi $_{10} \mathrm{Mg}+\mathrm{NiP}$ & - & $\sim 2$ & - \\
5 & ${ }^{d}$ Pol. AlSi $_{10} \mathrm{Mg}$ & - & $\sim 15$ & - \\
6 & ${ }^{d}$ Pol. Ti64 & - & $\sim 2$ & - \\
\hline
\end{tabular}

${ }^{d}$ Estimate based upon UCL measurement.

$\mathrm{Sa}=$ absolute mean, $\mathrm{Sq}=$ root mean square, $\mathrm{Sz}=$ peak-to-valley 
1

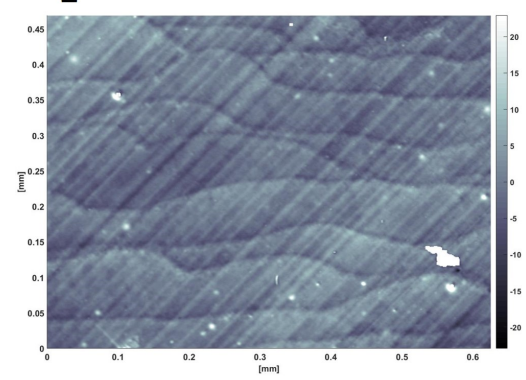

2

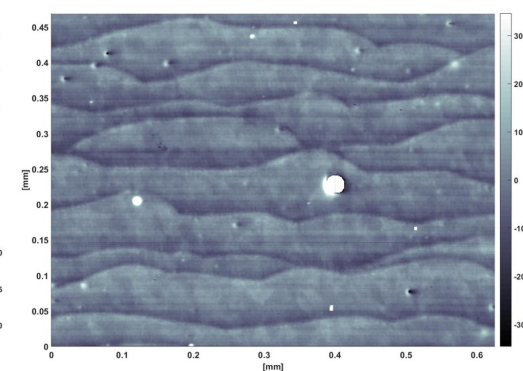

5

DT: $\mathrm{AlSi}_{10} \mathrm{Mg}$

10x magnification

Measurement area: $\sim 0.6 \mathrm{~mm} \times \sim 0.45 \mathrm{~mm}$
3

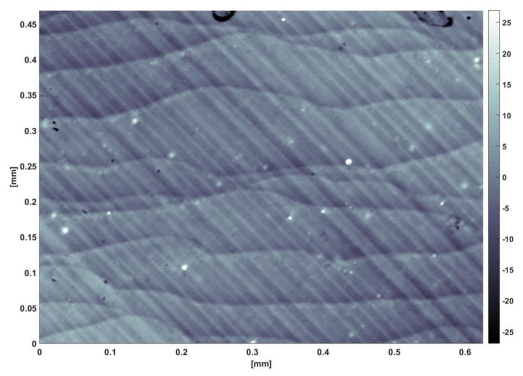

6

$(20,0)$
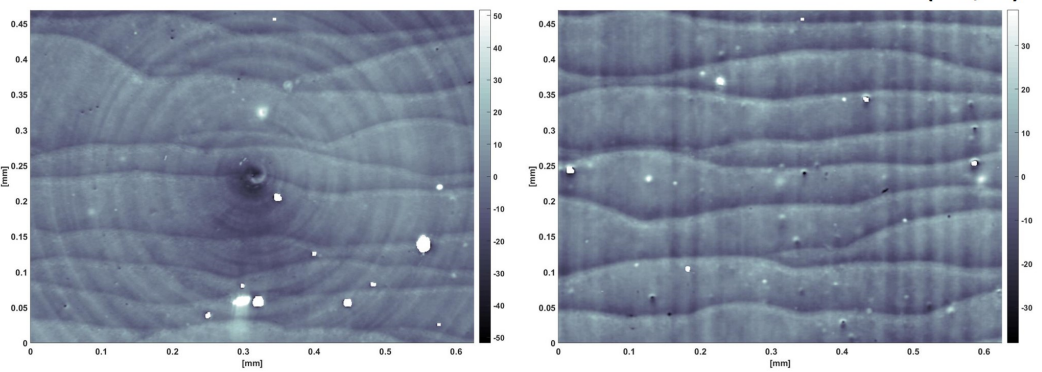

9

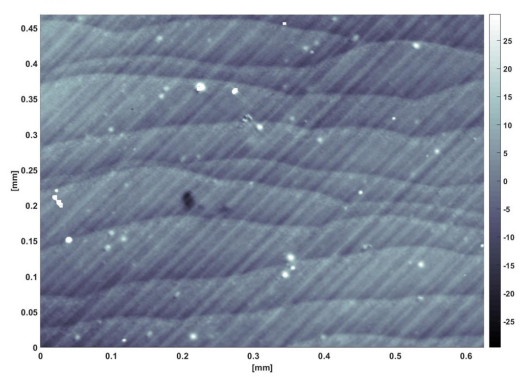

Figure 12. The surface roughness measurements of the DT $\mathrm{AlSi}_{10} \mathrm{Mg}$ mirror - the loss of data is highlighted as white pixels. 
1

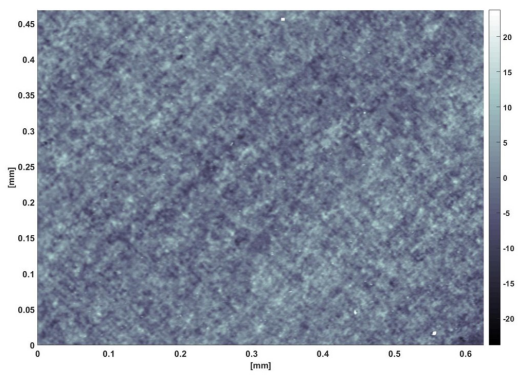

DT: RSA 6061

10x magnification

Measurement area: $\sim 0.6 \mathrm{~mm} \times 0.45 \mathrm{~mm}$
2

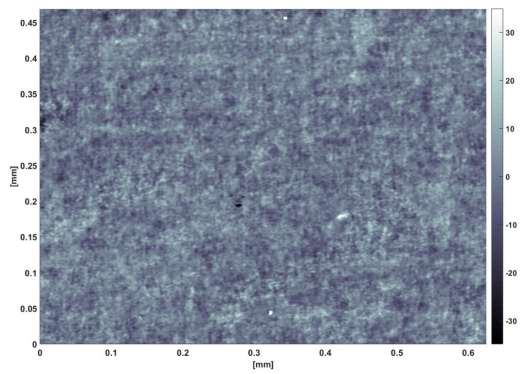

5

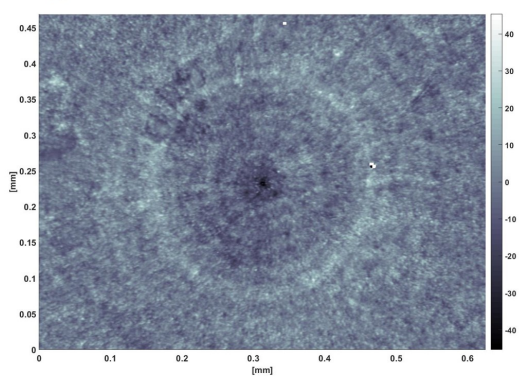

6

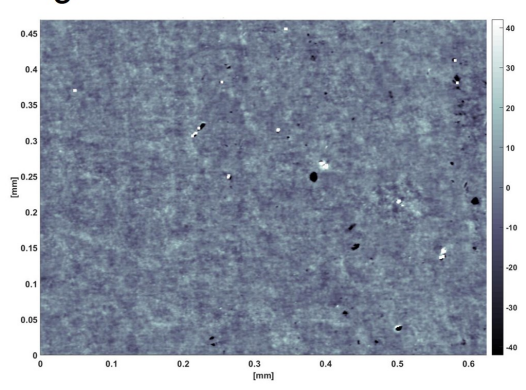

9

$(15,-15)$

\begin{tabular}{|r|r|r|r|r|r|}
\hline \multicolumn{7}{|c|}{ DT: RSA 6061 } \\
\hline$\#$ & Sa [nm] & Sq [nm] & Sp [nm] & Sv [nm] & Sz [nm] \\
\hline 1 & 2.69 & 3.39 & 36.89 & -16.75 & 53.64 \\
\hline 2 & 3.90 & 4.98 & 47.94 & -85.51 & 133.00 \\
\hline 3 & 2.91 & 3.67 & 24.74 & -15.54 & 40.28 \\
\hline 5 & 5.03 & 6.47 & 39.64 & -108.00 & 148.00 \\
\hline 6 & 4.05 & 6.34 & 250.00 & -276.00 & 526.00 \\
\hline 9 & 3.87 & 4.92 & 41.54 & -19.72 & 61.25 \\
\hline \multicolumn{7}{|c|}{} & & & & \\
\hline Average & $\mathbf{3 . 7 4}$ & $\mathbf{4 . 9 6}$ & $\mathbf{7 3 . 4 6}$ & $\mathbf{- 8 6 . 9 2}$ & $\mathbf{1 6 0 . 3 6}$ \\
\hline
\end{tabular}

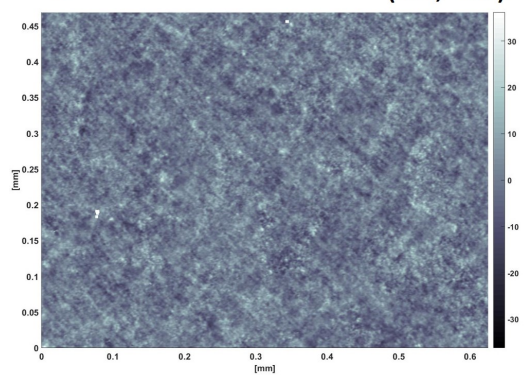

Figure 13. The surface roughness measurements of the DT RSA 6061 mirror. 
The DT $\mathrm{AlSi}_{10} \mathrm{Mg}+\mathrm{NiP}$ measurements (Figure 11) exhibit a low spatial frequency variation and measurement 5 (centre) highlighting a 'fan blade' pattern. It is suspected that this is an effect caused by vibration of the substrate during diamond turning and therefore can be considered as waviness as opposed to roughness. Therefore the Sq value of $5.64 \mathrm{~nm}$ represents an artificially high value than the actual roughness due to the contribution of the waviness.

Figure 12 presents the only direct measurement of an AM surface within the current data. Two features are evident within the interferograms: 1) the diamond turning lay lines whose orientation rotates around the centre point; and 2) the AM build lines, which run horizontally in each image. The horizontal builds lines are consistent with the orientation of the build and the positioning of the mirror upon the Bruker measurement platform, where $0^{\circ}$ represents the top of the build (as demonstrated in Figure 6) and is inline with the grid roughness measurements 2, 5 and 8. Despite the presence of the build layers, the Sq of the surface indicates $<5 \mathrm{~nm}$, which is considered a good roughness for cast aluminium and consistent with a similar reported Sq measurement of $3.66 \mathrm{~nm}$ on AM DT $\mathrm{AlSi}_{10} \mathrm{Mg}^{16}{ }^{1}$ However, as observed by the data loss (white pixels) and the higher value of $\mathrm{Sz}$, the surface is also prone to localised defects (pits and spikes) and the true value of Sq on the DT $\mathrm{AlSi}_{10} \mathrm{Mg}$ is suspected to be slightly higher.

The RSA 6061 sample (Figure 13) demonstrated typical roughness values for the aluminium type. The roughness was limited by the granularity of the material, which is visible in the image files. There are no significant defects in the RSA material and therefore although the RSA 6061 and the $\mathrm{AlSi}_{10} \mathrm{Mg}$ have similar Sq values, $4.96 \mathrm{~nm}$ and $4.85 \mathrm{~nm}$ respectively, the RSA 6061 has lower Sz values implying a better surface overall, which is to be expected for a non-AM material.

Figure 14 presents the total integrated scatter (TIS) of the three mirrors as a function of wavelength. The equation $^{17}$ TIS $=1-\exp \left(-(4 \pi \sin \theta \sigma / \lambda)^{2}\right)$ was used, where $\theta=$ the angle of incidence to the surface $\left(90^{\circ}\right), \sigma$ $=$ RMS roughness $(\mathrm{Sq})$ and $\lambda=$ the wavelength of light. TIS provides an estimation of the scatter assuming a Gaussian distribution of roughness. Figure 14 demonstrates that for all the mirrors there is $\leq 1 \%$ scatter at IR wavelengths $(>750 \mathrm{~nm})$ and that for the aluminium mirrors there is $\leq 2 \%$ at visible wavelengths $(400 \mathrm{~nm}$ to $750 \mathrm{~nm})$. Although the scatter for the $\mathrm{AlSi}_{10} \mathrm{Mg}+\mathrm{NiP}$ is greater than the aluminium, as discussed above, this value has been affected by the low order waviness in the measurement.

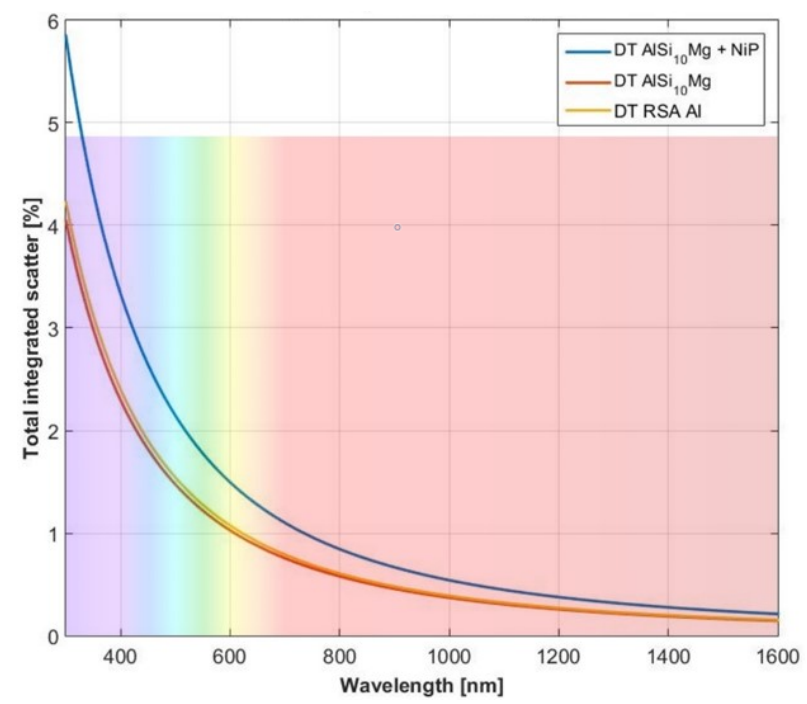

Figure 14. The total integrated scatter as a function of wavelength

\subsubsection{Anticipated roughness values for the polished mirrors}

To date only the diamond turned mirrors have been evaluated at DLS; however, the surface roughness of the polished mirrors has been measured during the polishing iterations at UCL. The Sq values are included within 
Table 5 and the results indicate that the Ti64 and $\mathrm{AlSi}_{10} \mathrm{Mg}+\mathrm{NiP}$ mirrors will demonstrate a high surface quality at approx. $2 \mathrm{~nm}$ for both substrates. The Sq value for the $\mathrm{AlSi}_{10} \mathrm{Mg}$ mirror predicts a rough surface of approx. $15 \mathrm{~nm}$, which is suspected to be a result of the multiple iterations of grounding and polishing that the substrate has experienced and encroaching the optical surface withing the porous layer as identified in Section 4.2.1.

\section{SUMMARY AND FUTURE WORK}

AM mirror fabrication has clear benefits in terms lightweighting and part consolidation if the required optical quality can be achieved. This paper has presented the design, fabrication and metrology of 5 AM mirrors designed for integration within a $3 \mathrm{U}$ CubeSat chassis. The primary goal of the study was to demonstrate how different AM materials, AM machines and post-processing routes can be implemented to create mirrors suitable for operation within the visible to IR wavelength range. The results to date are positive and encouraging with several routes for development identified.

Section 3 outlined the fabrication of mirrors, two different metal AM fabrication methods were trialled: laser powder bed fusion $\left(\mathrm{AlSi}_{10} \mathrm{Mg}\right.$ ) and electron beam powder bed fusion (Ti64). The analysis of the resulting mirrors was presented in Section 4, all except one of the AM mirrors exhibited a good surface quality (PVr between $130 \mathrm{~nm}$ to $300 \mathrm{~nm}$ and RMS between $25 \mathrm{~nm}$ to $35 \mathrm{~nm}$ ) after fabrication; however, the poor quality of the Pol. $\mathrm{AlSi}_{10} \mathrm{Mg}$ mirror ( $474 \mathrm{~nm}$ PVr and $83 \mathrm{~nm}$ RMS) was suspected to be due to the reworking that caused the optical surface to be generated within the layer of high porosity as indicated within the XCT measurements (Section 4.1). The anticipated scatter from the roughness on the diamond turned mirrors indicates current suitability within the IR wavelength range with $<1 \%$ scatter predicted. The $\mathrm{AlSi}_{10} \mathrm{Mg}+\mathrm{NiP}$ mirror, after filtering to removal the vibrational low order distortion, would arguably demonstrate reduced scatter.

Future work will target two areas: design optimisation and improvement of the AM material. The sister paper Atkins et al. $2019^{12}$ described the design logic and performance of the fabricated mirror design. The percentage of mass remaining after lightweighting of the fabricated design was $\sim 69 \%$, this value does not represent a significant weight saving at this stage; however, the priority of the project was the fabrication process chain of the AM mirrors the optical quality that could be achieved. From the optimisation study performed within the sister paper, several routes were identified for future lightweight mirror structures, which exhibit both a reduction in mass and in the predicted surface distortions. These structures will be developed further with input from both AM machine and subtractive machine operators to ensure a design that is optimised for function and post-processing.

The XCT data demonstrated the presence of porosity in close proximity to the depth where the optical surface would be generated. To reduce scatter and therefore improve the optical performance, minimising porosity is a priority. Working with the AM community, the porosity within the AM substrate can be reduced by altering the AM machine parameters ${ }^{15}$ and, in particular, the parameters can be tailored towards optical fabrication i.e. to prioritise a $100 \%$ dense material in the immediate vicinity where the optical surface will be generated. It is hoped that by tailoring the AM process to the end goal of mirror fabrication, an improvement in optical performance can be shown.

\section{ACKNOWLEDGMENTS}

The authors acknowledge the funding received by the UK Space Agency under grant agreement NSTP3-PF2-008 and express gratitude to the Department for Business, Energy \& Industrial Strategy and their support of the National Measurement System Programme which funded part of this work. Thanks are expressed to CA Models Ltd for their useful discussions and to the RAL Space PDF for assistance in the machining the AM substrates. Cyril Bourgenot acknowledges the Engineering and Physical Sciences Research Council (EPSRC) for support through the grant EP/S001727/1.

\section{REFERENCES}

[1] MTC, "Design for additive manufacture: metal powder bed fusion." Manufacturing Technology Centre (MTC) course notes (2018). 
[2] Vukobratovich, D., [Optomechanical Engineering Handbook - Chapter 5: Lightweight Mirror Design], CRC Press LLC (1999).

[3] Schwertz, K. and Burge, J. H., [Field Guide to Optomechanical Design and Analysis], SPIE Press (2012).

[4] Hilpert, E., Hartung, J., Risse, S., Eberhardt, R., and Tünnermann, A., "Precision manufacturing of a lightweight mirror body made by selective laser melting," Precision Engineering 0141-6359 (2018).

[5] Hilpert, E., Hartung, J., von Lukowicz, H., Herffurth, T., and Heidler, N., "Design, additive manufacturing, processing, and characterization of metal mirror made of aluminum silicon alloy for space applications," Optical Engineering 58(9) (2019).

[6] Herzog, H., Segal, J., Smith, J., Bates, R., Calis, J., De La Torre, A., Kim, D. W., Mici, J., Mireles, J., Stubbs, D. M., and Wicker, R., "Optical fabrication of lightweighted 3d printed mirrors," Proc. SPIE 9573, 957308-957308-15 (2015).

[7] Sweeney, M., Acreman, M., Vettese, T., Myatt, R., and Thompson, M., "Application and testing of additive manufacturing for mirrors and precision structures," Proc. SPIE 9574, 957406-957406-13 (2015).

[8] Mici, J., Rothenberg, B., Brisson, E., Wicks, S., and Stubbs, D. M., "Optomechanical performance of 3dprinted mirrors with embedded cooling channels and substructures," Proc.SPIE 9573, 9573 - 9573 - 14 (2015).

[9] Hu, R., Chen, W., Li, Q., Liu, S., Zhou, P., Dong, Z., and Kang, R., "Design optimization method for additive manufacturing of the primary mirror of a large-aperture space telescope," Journal of Aerospace Engineering 30(3), 04016093 (2017).

[10] Liu, J. and Jiang, B., "Topology optimization design of a space mirror," Proc. SPIE 9795, 97952Y-97952Y$10(2015)$.

[11] Qu, Y., Wang, W., Liu, B., and Li, X., "Topology optimization design of space rectangular mirror," Proc. SPIE 10154, 1015421-1015421-7 (2016).

[12] Atkins, C., Brzozowski, W., Dobson, N., Milanova, M., Todd, S., Pearson, D., Brooks, D., Bourgenot, C., Snell, R. M., Sun, W., Cooper, P., Alcock, S. G., and Nistea, I.-T., "Lightweighting design optimisation for additively manufactured mirrors," Proc. of SPIE 11116-42 (2019).

[13] Allthorpe-Mullis, E., Brzozowski, W., Easdown, W., Feore, D., Grainger, W., Greenland, S., Hodgkins, M., Milanova, M., Payne, S., Pearson, D., Rowan, C., and Todd, S., "Cubesat camera: A low cost imaging system for cubesat platforms," Proceedings of iCubeSat 2018 (2018).

[14] Cooper, P. A., Sun, W., Atkins, C., and Brown, S. B., "Micro xct measurements of defects in light-weighted mirrors for applications in space imaging," Proc. of BINDT 2019 (2019).

[15] Tammas-Williams, S., Zhao, H., Lonard, F., Derguti, F., Todd, I., and Prangnell, P., "Xct analysis of the influence of melt strategies on defect population in ti6al4v components manufactured by selective electron beam melting," Materials Characterization 102, 47 - 61 (2015).

[16] Atkins, C., Feldman, C., Brooks, D., Watson, S., Cochrane, W., Roulet, M., Hugot, E., Beardsley, B., Harris, M., Spindloe, C., Alcock, S. G., Nistea, I.-T., Morawe, C., and Perrin, F., "Topological design of lightweight additively manufactured mirrors for space," Proc. of SPIE 10706 (2018).

[17] Friedman, E. and Miller, J. L., [Photonics Rules of Thumb], McGraw-Hill, second ed. (2004). 